\title{
Inhaltsverzeichnis
}

Vorwort . . . . . . . . . . . . . . . . VII

LEo Stern

Der Uberfall des faschistischen Deutschlands auf die Sowjetunion und die Lehren für die Gegenwart . . . . . . . . . . . . . . 1

E. A. Boltin

Der Große Vaterländische Krieg der Sowjetunion gegen den deutschen Faschismus - ein gerechter Volkskrieg zur Verteidigung der sozialistischen Sowjetunion und der gesamten Menschheit . . . . 17

\section{WALDEMAR VERNER}

Die deutschen Militaristen haben gegen den Sozialismus keine Chance .. . . . . . . . . . . . . . . . . 44

N. A. FoxIN

Das Scheitern des faschistischen Blitzkrieges gegen die UdSSR und das Entstehen der Voraussetzungen für den grundlegenđen Umschwung im Verlauf des Großen Vaterländischen Krieges der Sowjetunion . . . . . . . . . . . . . . . . 73

\section{Otтo SchwaB}

Wehrmachtmanöver - Vorstufen und Generalproben für die Aggressionspläne des deutschen Militarismus . . . . . . . 103

G. L. Rosanow

Der Kampf der Sowjetunion für die Bildung und Festigung einer antifaschistischen Koalition und ihre Rolle bei der Zerschlagung des faschistischen Deutschland . . . . . . . . . . . . 114 


\section{STEFAN DOERnBERG}

Die Teilnahme deutscher Antifaschisten am Großen Vaterländischen Krieg der Sowjetunion - Ausdruck des proletarischen Internationalismus und wahren Patriotismus . . . . . . . . . 129

E. A. Boltin

Uber einige Methoden der Verfälschung der historischen Wahrheit in dem Buch von H. A. Jacobsen und Jürgen Rohwer "Entscheidungsschlachten des zweiten Weltkrieges" . . . . . 139

\section{Rudi Goguel}

Der Einfluß der wachsenden Stärke des sozialistischen Lagers auf einige ideologische Konzeptionen der westdeutschen Ostforschung 149

G. N. Goroschrowa

Gegen die Verfälschung der sowjetischen Politik in der deutschen Frage . . . . . . . . . . . . . . . . . . . . . 185

Personenregister . . . . . . . . . . . . . . . . 201

Autorenverzeichnis . . . . . . . . . . . . . . . . . . . . . . . 205 